Original research paper

\title{
Anti-inflammatory and analgesic effect of an alkaloid-fixed oil mix from Linumusitatisimum seeds in vivo
}

\author{
Ferhat $\mathbf{R}^{1}$, Bribi ${ }^{1}$, Merakeb M.S ${ }^{1}$, Yanat B ${ }^{1}$ \\ ${ }^{1}$ Laboratory of Biochemistry and Biotechnology, Faculty of Natural and Life Sciences, University of \\ Bejaia, 06000 Bejaia, Alegria...
}

Corresponding Author: Ferhat R, University Abderrahmane Mira, Bejaia, Algeria Email:ferriad@hotmail.fr

\begin{abstract}
Inflammation is an immune response to chemical, physical or biological aggression. The comprehension of the several pro-inflammatory and pro-resolving process may lead to the development of new functional drugs instead of the conventional ones. However, Inflammation reaction is conventionally treated by steroidal and nonsteroidal anti-inflammatory drugs. These medications may be useless because of their side effects. In this study, we aim to evaluate the anti-inflammatory and analgesic effect of alkaloid /fixed oil mixture (AO) from flaxseeds in-vivo. Three doses of AO mix $(50,100$ and $200 \mathrm{mg} / \mathrm{kg}$ ) were used in several anti-inflammatory and analgesic tests. The obtained results had shown that the AO mix presents a potential anti-inflammatory and analgesic activities. These results highlight the therapeutic potential of alkaloids and fixed oils combination. Additionally, to other research, the present study supports the anti-inflammatory and analgesic effects of flax seeds with an original contribution by combining alkaloids and fixed oil from Linumusitatissimum.
\end{abstract}

Keywords: Inflammation, anti-inflammatory, analgesic, Linumusitatissimum, Alkaloid, fixed Oil.

\section{Introduction}

Inflammation is an immune response to chemical, physical or biological aggression; it is characterized by several events resulting in the formation of edema by an inflammatory mediators release such as bradiykinin, serotonin, histamine, leukotrienes and prostaglandins(Macedo et al., 2019). The understanding of how the inflammatory process is activated and the comprehension of the high plasma expression of pro-inflammatory cytokines like interleukine (IL-1), IL-6 and tumor and necrosis factor $\alpha$ (TNF- $\alpha$ ) may lead to the development of strategies to block or reduce the inflammation response(Ward and Lentsch, 1999).Inflammatory reaction can be devised in 3 phases: Silent phase, vascular phase and cellular phase. This reaction leads to a sensory response including pain, hyperalgesia and allodynia. Any inflammatory process inappropriate regulation may lead to significant tissue dysfunctions which are translated into several inflammatory diseases such as arthritis, inflammatory bowel disease and asthma(Vergnolle, 2003).

The inflammation is naturally resolved with cellular and molecular mediators, the inflammatory response is characterized by increased blood flow, capillary dilatation and leucocytes infiltration especially neutrophils which plays a key role in the inflammation process. However, during the inflammation resolution we can observe the depletion of neutrophils from the inflamed site through a programmed process that is regulated at multiple levels. In addition, several cellular and molecular process occur when inflammation resolution process is activated like: the counter regulation of chemokines and cytokines, the switching off of signalling pathways associated with leukocytes survival, the reprogramming of macrophages from classically activated to alternatively activated cells and finally the initiation of healing process (Sugimoto et al., 2016)

The comprehension of the several pro-inflammatory and pro-resolving process may lead to the development of new functional drugs instead of the conventional ones. Inflammation reaction is conventionally treated by steroidal and nons-teroidal anti-inflammatory drugs (SAIDs, NSAIDs) to relief pain and inflammation. However, these medications may be useless because of their side effects. 
New researches are nowadays recommending the use of medicinal plants that have a higher interest and present a minimum of side effects(Bribi et al., 2016; Rafieian-kopaei et al., 2017a).

Linumusitatisssimum that belong to Lineaceae family is an annual plant known to be used in food and textile industries. The flax seeds oil is also known, due to its high content of polyunsaturated fatty acids, to have a wide range of health benefits. (De Santana Lopes et al., 2018; Kaithwas et al., 2011). On the basis of previous work, in which Linumusitatissimum had been reported as a plant with biological effects on acute and chronic arthritic albinos rat (Kaithwas and Majumdar, 2010b), antibacterial activities of hydrolysed lipid against $S$. aureus resistant to antibiotics (Mcdonald et al., 1981) and an antiulcer activity of flaxseed oil in animal model (Kaithwas and Majumdar, 2010a), these pharmacological activities shows the high interest of this plant (Kaithwas et al., 2011).In this study, we aim to evaluate the antiinflammatory and analgesic effect of alkaloid /fixed oil mixture(AO mix) from flaxseeds in vivo

\section{Material and methods}

\section{Drugs and chemicals}

All substances were purchased from Sigma-Aldrich Chemical (Madrid-Spain), unless otherwise stated. The test substances were dissolved in distilled water and prepared fresh daily for administration to the animals.

\section{Animals}

Healthy male albino NMRI mice (26-32 g) from the Laboratory Animal Service of the University of Bejaia (Algeria), were maintained under standard laboratory conditions with free access to tap water and food.The experimental protocol was carried out in accordance with the 'Guide for the Care and Use of Laboratory Animals as promulgated by the National Institute of Health, and the protocol approved by the local Ethics Committee of the laboratory of PBVE, University of Bejaia, (Ref. No. CE-LBVE2017-107).

\section{Alkaloids extraction}

In the present study we used Linumustitatissimum seeds (flax seeds) from commercial source at Bejaia city. The alkaloid extraction were performed following Soušek protocol (Soušek et al., 1999). Briefly, the flaxseeds powder was extracted with methanol for $8 \mathrm{~h}$ in a Soxhlet apparatus, and then evaporated under reduced pressure, acidified with 2.5\% HCL to $\mathrm{pH} \mathrm{1-2} \mathrm{and} \mathrm{filtered,} \mathrm{and} \mathrm{stored} \mathrm{at} \mathrm{room} \mathrm{temperature}$ overnight. The aqueous acid solution was adjusted to $\mathrm{pH}=9.5$ with concentrated ammonium hydroxide and extracted with dichloromethane. The extracts were evaporated to afford a crude extract of total alkaloids. After evaporation the alkaloid extract of Linumustitatissimum (ALU) obtained was stored at $4^{\circ} \mathrm{C}$ until use.

\section{Fixed oils extraction}

Flaxseeds were washed and grinded then macerated in methanol under agitation, the fixed oils extraction was a solid-liquid extraction. In brief, $500 \mathrm{ml}$ methanol was added to $50 \mathrm{~g}$ of flax seed powder, after maceration we performed a phases separation to recover the fixed oil after evaporation(Danlami et al., 2014). Due to miscibility of fixed oil we dissolved it in tween 20.

\section{Mouse ear edemainduced by xylene}

In a first time, edema induced by the topical application of chemical irritants was measured as an increase in ear thickness, the chemical irritant ( $30 \mu \mathrm{l}$ of Xylene) was pipetted directly into the ears of the mice. Ear thickness was assessed with an electronic digital micrometre (Starrett Series 734) applied near the tip of the ear distal to the cartilaginous ridges; the difference in thickness between the basal measurement and after challenge was calculated (Macedo et al., 2019). Treatment was applied with oral administration of AO mix (50,100 or $200 \mathrm{mg} / \mathrm{kg})$, and diclofenac $(5 \mathrm{mg} / \mathrm{kg})$ or local application of AO $\operatorname{mix}(0.25,0.5$ or $1 \mathrm{mg} / \mathrm{kg})$ and diclofenac $(0.5 \mathrm{mg} / \mathrm{kg})$

In a second time, the test of xylene-induced ear edema in mice was based on the reported method ( Nunez-Guillen et al., 1997; Akindele and Adeyemi, 2007). Briefly, thirty minutes after oral administration of AO mix (50, 100 or $200 \mathrm{mg} / \mathrm{kg})$, and diclofenac $(5 \mathrm{mg} / \mathrm{kg})$, an edema was induced in 
the right ear by topical application of $30 \mu \mathrm{l}$ xylene applied near the tip of the ear distal to the cartilaginous ridges.After $15 \mathrm{~min}$, the mices were sacrificed by cervical dislocation. Circular sections of $7 \mathrm{~mm}$ diameter were removed from each ear using a cork borer and weighted. The edema degree was responded with the difference in weight between treated and no-treated earfromeachmouse to evaluate the effect of AO mix. The anti-inflammatory effect was expressed as percentage of the inhibition of the oedema (PI). This percentage was calculated using the following formula:

$$
\mathrm{PI}=\frac{\text { Difference in ear weight,control }- \text { Difference in ear weight,treated }}{\text { Difference in ear weight,control }} X 100 .
$$

\section{Acetic acid-induced writhing response}

The writhing test was carried out as previously described(Koster et al, 1959). Mice were randomly assigned to five groups, and after an overnight fasting period, they were pre-treated with AO mix (50, 100 or $200 \mathrm{mg} / \mathrm{kg}$, p.o.), diclofenac ( $100 \mathrm{mg} / \mathrm{kg}$,p.o.), or distilled water (control group, p.o.), $60 \mathrm{~min}$ before the acetic acid injection $(10 \mathrm{~mL} / \mathrm{kg}$ body weight, i.p.). Immediately after the injection of acetic acid, each animal was placed in a transparent plastic observation chamber. Five minutes after the administration of $1 \%$ aceticacid ${ }^{v / v}$, the number of writhes and stretching movements of each mouse was counted for a period of $15 \mathrm{~min}$. The percentage of inhibition of writhing was calculated and compared with the control group using the expression: Inhibition $(\%)=\frac{\mathrm{WC}-\mathrm{WT}}{\mathrm{WC}} X 100$; WC: mean of writhing (control); WT: mean of writhing (test).(Bribi et al., 2016)

\section{Formalin-induced Licking paw}

The formalin test was performed as previously reported(Hunskaar and Hole, 1987; Tjølsen et al., 1992). Briefly, overnight fasted mice were divided into five groups, which received distilled water $(10 \mathrm{~mL} / \mathrm{kg}$, p.o.), AO mix (50, $100 \mathrm{or} \mathrm{mg} / \mathrm{kg}$, p.o.), or diclofenac (100 mg/kg, p.o.) $1 \mathrm{~h}$ before formalin injection (20 $\mu \mathrm{L}$ of $1 \%$ formalin) under the plantar surface of the right hind paw. The micewere then placed in a transparent box for observation, and the time spent licking the injected paw was measured and considered as an indication of inflammatory-associated pain. The first phase of the nociceptive response normally peaks $0-5$ min after injection and the second phase $15-30$ min after.

\section{Tail-immersion test}

The tail immersion test was used to evaluate thermal-induced pain following Swell and Spincer(Sewell and Spencer, 1976). Briefly, each mouse was placed in a holder with its tail portending. The tail was placed in a hot water bath at $50 \pm 2 \mathrm{C}^{\circ}$ until the tail whipped or a flinch of body occurred. A cut off time of 15 seconds was imposed. Mice were treated for control test and Mix (50, 100 and $200 \mathrm{mg} / \mathrm{kg}$ ) analgesic effect. The anti-nociceptive response was calculated as follow:

$\%$ anti-nociception $=\frac{T-C}{15-C} \times 100$

Where $\mathrm{C}$ and $\mathrm{T}$ represent the tail whip reaction time in seconds prior to narcotic injection (C) and at the peak time (T) after the day injection(Statile et al., 1988).

\section{Statistical analysis}

All data were expressed as mean \pm standard error of the mean (SEM). The statistical analysis of all the observations was carried out using one-way ANOVA followed by multiple comparison test of Dunnett's, where necessary. A difference of $\mathrm{p}<0.05$ was considered as significant compared with the negative control (treated with vehicle).

\section{Results and discussion}

Anti-inflammatory activity

\section{Xylene induced-ear edema}

The evaluation of anti-inflammatory effect ofthe alkaloids-fixed oils mix (AO) extract from Linumusitatissimum was performed through a xylene induced-ear oedema following different measurement and treatment modalities. The oral and local administrations of (AO) of Linumusitatissimum produced a marked analgesic and anti-inflammatory effects in models of pain and 
inflammation. The results of inhibition of the xylene-induced ear edemain mice are presented as means \pm SEM.

In a first place, we realized a measure of ear thickness with two treatment administration ways; local administration (AO mix 0.25, 0.5 and $1 \mathrm{mg} / \mathrm{kg}$, diclofenac $0.5 \mathrm{mg} / \mathrm{kg}$ ). The results are presented in (Figure 1: A), these results show a significant inflammation inhibition by the different AO mix doses $(0.25,0.5$ and $1 \mathrm{mg} / \mathrm{kg})$ with respectively $42.5 \%, 51.8 \%$ and $69.98 \%$. Indeed, AO mix shown a dose dependant anti-inflammatory that was close to $5 \mathrm{mg} / \mathrm{kg}$ diclofenac effect $(75.09 \%)$ with a $1 \mathrm{mg} / \mathrm{kg} \mathrm{AO}$ mix dose.

Then, we performed an oral administration of 3 doses of AO mix $(50,100$ and $200 \mathrm{mg} / \mathrm{kg})$, and diclofenac $(5 \mathrm{mg} / \mathrm{kg}$ ), the results are presented in (Figure 1: B). In this case, AO mix doses and diclofenac also shown a significant reduction of ear edema $(* * * \mathrm{P}<0.001)$. The $5 \mathrm{mg} / \mathrm{kg}$ diclofenac dose has an inflammatory inhibition percentage as high as the $200 \mathrm{mg} / \mathrm{kg}$ AO mix dose with $74.25 \%$ and $80.83 \%$ respectively. The differences between the results of the two administration modalities may be due to the pharmacological proprieties of the active molecules among the AO mix of flax seeds, which leads to realise more pharmacological and toxicological investigations.
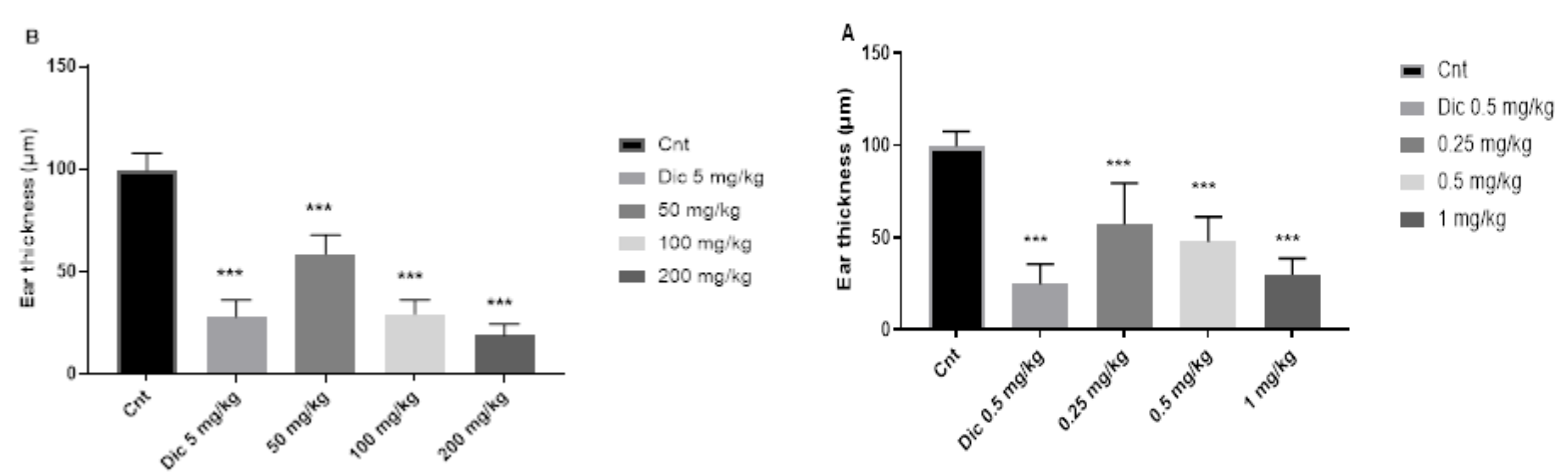

Figure 1. Anti-inflammatory effect of AO Mix on mousse ear oedema induced by Xylene. (A): PI \% with local administration "per se", (B): Ear thickness with local administration "per se", (C): PI \% with oral administration "per os", (D): Ear thickness with oral administration "per os".

In a second place, we investigate the difference between ears weight (Control ear - treated ear). The results presented in Figure 2shows low PI (\%) for the $50 \mathrm{mg} / \mathrm{kg}$ dose of AO mix and no statistical significance. However, $100 \mathrm{mg} / \mathrm{kg}$ and $200 \mathrm{mg} / \mathrm{kg}$ presented a better effect; the $200 \mathrm{mg} / \mathrm{kg}$ dose of AO mix was even higher than the $5 \mathrm{mg} / \mathrm{kg}$ diclofenac dose with $62.9 \%$ against $47.26 \%$.

Xylene is one of common pollutants in the plastic, chemical and leather industries. Skin contact with this chemical substance may result in local disorders such as irritant dermatitis or allergic dermatitis(Sasseville, 2008).An investigation about the role of TRPA1 receptors in skin inflammation induced by volatile chemical irritant shows that Xylene may promote vascular reaction mediated by TRPA 1 receptor signalling while this channel is expressed in many non-neuronal cell such as mast cell, keratinocytes and melanocytes. In addition, this study has also established that TRPV1 may work in a synergic manner with TRPA1 to mediate the cutaneous inflammatory response caused by xylene (Norões et al., 2019).

Another study about effect of flaxseed fixed oil against distinct phases of inflammation had shown that L.usitatissimum fixed oil significantly reduced the peritoneal vascular permeability, indicating the suppression of the vascular response during the acute inflammation. Also, faxseed fixed oil inhibited the leucocytes migration (Kaithwas and Majumdar, 2013).Furthermore, it has been established that faxseed oil had a beneficial effect in diet which might be due to the modulation of omega- 6 availability and immunological homeostasis (Singh et al., 2012).In the light of this investigation, AO mix could combine additionally or synergically the immunological modulation of each alkaloids and fixed oil frome L.usitatissimum. 
Taken together, these results show the anti-inflammatory effect of AO mix in the Xylene induced ear oedema. Several studies used this acute inflammation model induced by Xylene for its capacity to promote inflammation especially through enzymatic pathway such as phospholipase $\mathrm{A}_{2}$ (Bribi et al., 2016; Macedo et al., 2019)

The several comparative graphs in Figure 3(A and B) that shows the administration modalities (local or oral) and the PI (\%) measurement, leads to the same results highlighting the regular anti-inflammatory effect of AO mix which seems to be a dose-dependent effect.

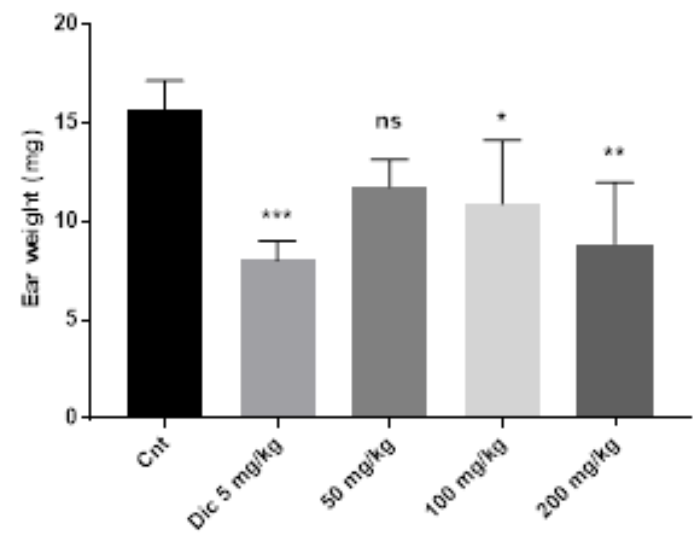

Fig 2. Anti-inflammatory effect of AO mix and diclofenac on Xylene induced ear oedema, (A): PI (\%) calculated from weight difference between control and treated ear. (B): Weight differences between control and treated ear $(\mathrm{mg})$. $* * * \mathrm{P}<0.001, * * \mathrm{P}<0.01, * \mathrm{P}<0.05$, ns $\mathrm{P}>0.05$ vs control group (cnt).
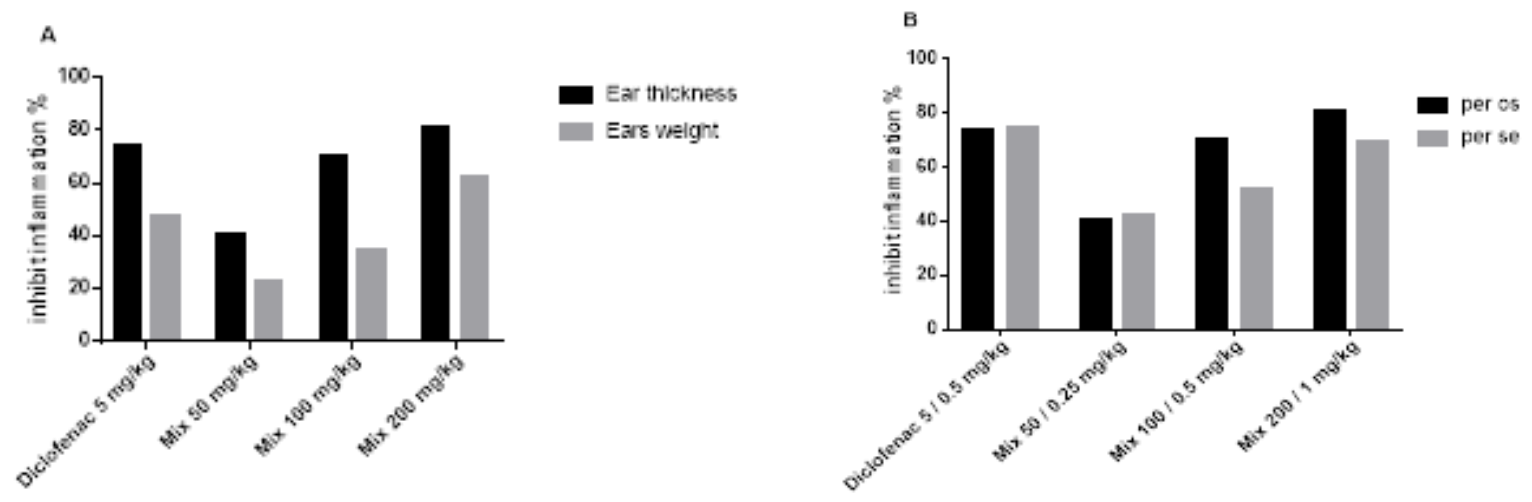

Figure 3 Treatment and measurement modalities dependent Anti-inflammatory effect of AO mix and Diclofenac, (A): compare between PI (\%) of different oedema measurement (Ear thickness and Ears weight), (B); compare between PI(\%) of different application modalities (per os and per se).

The results presented in Figure 4(A) shows a significant analgesic effect of the Ao mix $(\mathrm{P}<0.001$ vs the control group). The Figure 5 (B) shows a writhing response inhibition percentage higher than $80 \%$ for 50,100 and $200 \mathrm{mg} / \mathrm{kg}$ doses of $\mathrm{AO}$ mix. 


\section{Analgesic activity}

Acetic acid-induced writhing response

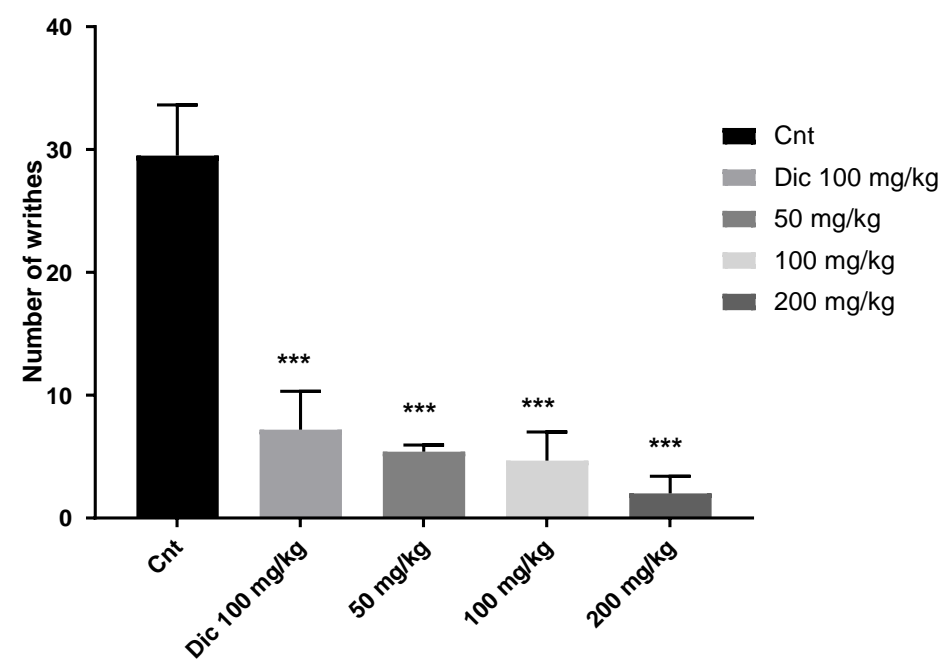

Figure 4 Analgesic effect of AO mix on mice acetic acid-induced writhing response. (A): Number of writhe, (B): percentage of writhing response inhibition. $* * * \mathrm{P}<0.001 \mathrm{Vs}$ control group (cnt).

The acetic acid injection in the peritoneal cavity can induce an inflammatory response followed by a sensorial one, which leads to the release of several inflammatory and hyperalgesia mediators that promote the exciting of nerves extremities translated into the symptomatic writhing response(Bribi et al., 2016).Local tissue injury prompts the release of chemical mediators (potassium, hydrogenions, and bradykinin) and inflammatory mediators as prostaglandinE2 (PGE2) frominflammatory cells. These substances directly activate nerve endings and trigger the release of algesic mediators (for example, histamine, serotonin (5-HT), nerve growth factor (NGF), and prostanoids) from other cells and afferent nerves(Bribi, 2018).

\section{Licking paw test}

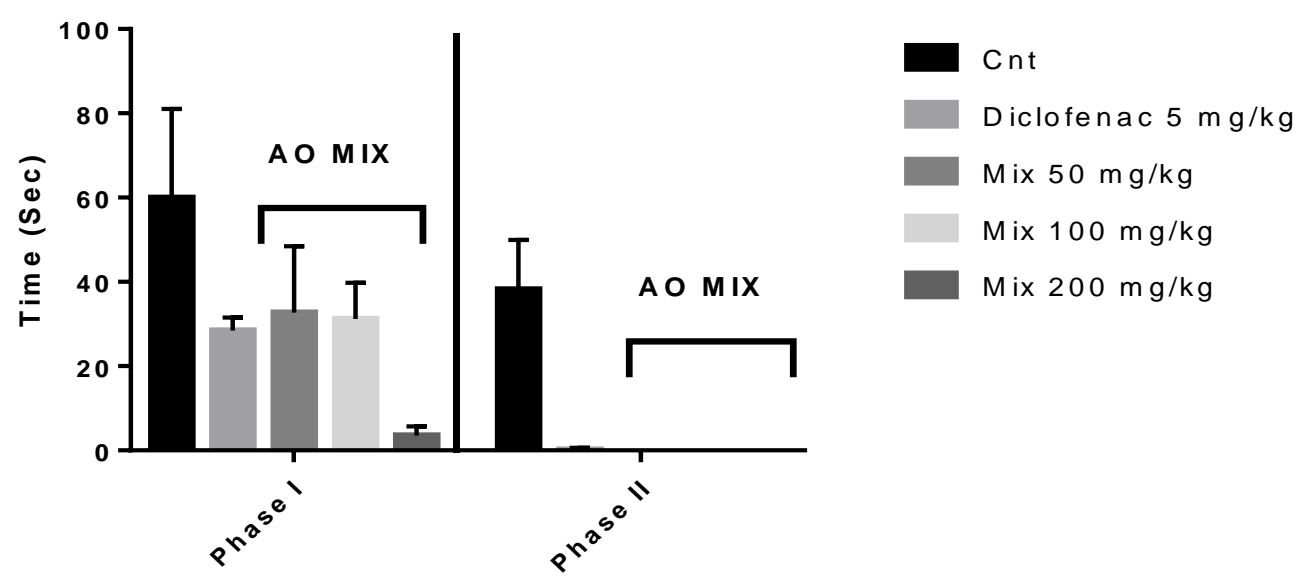

Figure 5. Analgesic effect of AO mix (50, 100 and $200 \mathrm{mg} / \mathrm{kg}$ ) on formalin-induced leaking paw test.

The formalin induced leaking paw test is a communally used analgesic test, divided into two successive phases the first one shows the anti-nociceptive response while the second one shows the antiinflammatory response. The AO mix $(50,100$ and $200 \mathrm{mg} / \mathrm{kg}$ ) effect on the first phase (antiinflammatory phase) approve the anti-inflammatory effect of AO mix previously evaluated (Figure 1,2 and 3), translated in a significant reduction of licking time compare to the control group. The $200 \mathrm{mg} / \mathrm{kg}$ does of AO mix had reveal a significant anti-inflammatory effect on the first phase even compared to 5 
$\mathrm{mg} / \mathrm{kg}$ diclofenac effect. In the second phase (anti-nociceptive), the three doses of AO mix (50, 100 and $200 \mathrm{mg} / \mathrm{kg}$ ) had shown a significant analgesic effect with no licking time.

The tail immersion test
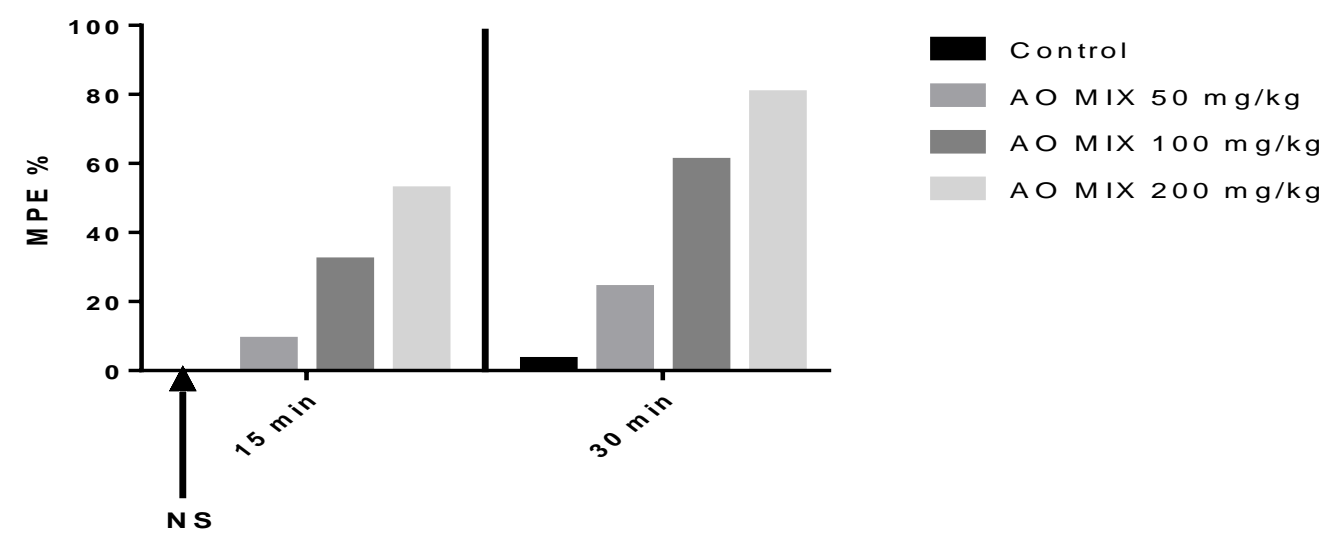

Figure 6. Anti-nociceptive effect of Ao Mix (50,100 and $200 \mathrm{mg} / \mathrm{kg}$ ) on Tail Immersion Test

The tail immersion test used in this study was performed to evaluate the central nociceptive effect of AO Mix. The results show that Ao mix had a dose dependent analgesic effect with the high MPE $\%$ at the highest AO Mix dose (200 mg/kg) during the two phases of the test (0-15 and 0-30).

Taken together, these results highlight the analgesic effect of linumusitatissimum on the different analgesic tests performed in this study. In fact, both formalin induced paw licking test and tail immersion test coordinate with the acetic acid-induced writhing response results showing that AO mix had peripheral and central anti-nociceptive effect, since assayed analgesic tests in this investigation evaluate peripheral and central analgesic effect.In previous studies, anti-inflammatory and analgesic effect of effective compounds in nociception have been attributed to some alkaloids, flavonoids, organic acids or caffeic acid derivatives (Rafieian-kopaei et al., 2017b).

It appears that the combination of alkaloids and organic acid in the fixed oil have an additional or synergic analgesic effect. Substances characterisation is needed to determinate which compound in the AO Mix is responsible of either analgesic or anti-inflammatory activity or even the two activities at the same time, considering that pain and inflammation are much related possess.

\section{Conclusion}

The alkaloids/fixed oil mixture from Linumusitatissimum(Flax seeds) shows a significant antiinflammatory and analgesic activity in-vivo, these results highlight the therapeutic potential of alkaloids and fixed oils combination which may combine different actives compounds acting with different mechanisms in an additional or synergical ways. Additionally, to other research, the present study supports the anti-inflammatory and analgesic effects of flax seeds with an original contribution by combining alkaloids and fixed oil from Linumusitatissimum.

\section{Author's Contributions}

Riad Fehat, Mohamed sofiane Merakeb and Noureddine Bribi performed the experiments and contributed to the acquisition and analysis of data.Riad Ferhat, Noureddine Bribiand BetitraYanat contributed to the analysis and interpretation of data, designed the experiments and wrote the manuscript.

\section{Conflicts of interest}

All authors declare that there is no conflict of interest 


\section{References}

Akindele GA. Adeyemi OO 2007. Antiinflammatory activity of the aqueous extract of Byrsocarpus coccineus. Fitote, 78, 25-28.

Bribi N. Belmouhoub M. Maiza F 2016. Anti-inflammatory and analgesic activities of ethanolic extract of Fumaria capreolataActivités anti-inflammatoire et analgésique de l'extrait éthanolique de Fumaria capreolata. Phytothérapie, 15(4), 211-216. https://doi.org/10.1007/s10298-016-1035-6

Bribi N 2018. Anti-nociceptive and anti-inflammatory effects of Paeonia mascula extract. Journal of Pharmacy \& Pharmacognosy Research, 6(2), 81-88.

Danlami JM. Arsad A. Zaini MAA. Sulaiman H 2014. A comparative study of various oil extraction techniques from plants. Reviews in Chemical Engineering, 30(6), 605-626. https://doi.org/10.1515/revce-2013-0038

De Santana Lopes A. Pacheco TG. Santos KG. dos Vieira L. do N. Guerra MP. Nodari RO. de Souza EM. de Oliveira Pedrosa F. Rogalski M 2018. The Linum usitatissimum L. plastome reveals atypical structural evolution, new editing sites, and the phylogenetic position of Linaceae within Malpighiales. Plant Cell Reports, 37(2), 307-328. https://doi.org/10.1007/s00299-017-2231-z

Hunskaar S. Hole K 1987. The formalin test in mice: dissociation between inflammatory and noninflammatory pain. Pain. https://doi.org/10.1016/0304-3959(87)90088-1

Kaithwas G. Majumdar DK 2010a. Evaluation of antiulcer and antisecretory potential of Linum usitatissimum fixed oil and possible mechanism of action. Inflammopharmacology. https://doi.org/10.1007/s10787-010-0037-5

Kaithwas G. Majumdar DK 2010b. Therapeutic effect of Linum usitatissimum (flaxseed/linseed) fixed oil on acute and chronic arthritic models in albino rats. Inflammopharmacology.

Kaithwas G. Majumdar DK 2013. Effect of L. usitatissimum (Flaxseed/Linseed) Fixed Oil against Distinct Phases of Inflammation . ISRN Inflammation, 2013, 1-4. https://doi.org/10.1155/2013/735158

Kaithwas, G., Mukerjee, A., Kumar, P., \& Majumdar, D. K. 2011. Linum usitatissimum (linseed/flaxseed) fixed oil: Antimicrobial activity and efficacy in bovine mastitis. Inflammopharmacology, 19(1), 45-52. https://doi.org/10.1007/s10787-010-0047-3

Koster R. Anderson M. De Beer E 1959. Acetic Acid for Analgesic Screening. Federation Proceedings, 18, 412-417.

Macedo M. Gonzaga L. Cristina E. Paula V. De Rachetti S. Fleith M. Almeida D. De Prudente S. Raíza J. Matias J. Carvalho M. De Ferreira J. Preti D. Logu F. De Nassini R. André E 2019. Role of TRPA1 receptors in skin inflammation induced by volatile chemical irritants in mice. $\begin{array}{llll}\text { European Journal of } & \text { Pharmacology, } & \text { 858(March), } & 172460 .\end{array}$ https://doi.org/10.1016/j.ejphar.2019.172460

Mcdonald MI. Graham I. Harvey KJ. Sinclair A 1981. Antibacterial activity of hydrolysed linseed oil and linolenic acid against methicillin-resistant staphylococcus aureus. In The Lancet. https://doi.org/10.1016/S0140-6736(81)91261-7

Norões MM. Santos LG. Gavioli EC. de Paula Soares Rachetti V. Otuki MF. de Almeida Cabrini D. da Silveira Prudente A. Oliveira J RJM. de Carvalho Gonçalves M. Ferreira J. Preti D. De Logu F. Nassini R. André E 2019. Role of TRPA1 receptors in skin inflammation induced by volatile chemical irritants in mice. European Journal of Pharmacology, 858(March), 172460. https://doi.org/10.1016/j.ejphar.2019.172460

Nunez-Guillen ME. Emim JA. Souccar C. et al. 1997. Analgesic and anti-inflammatory activities of the aqueous extract of Plantago major L. Int J Pharm, 35, 99-104.

Rafieian-kopaei M. Shakiba A. Sedighi M. Bahmani M 2017a. The Analgesic and AntiInflammatory Activity of Linum usitatissimum in Balb/c Mice. Journal of Evidence-Based Complementary and Alternative Medicine, 22(4), 892-896. https://doi.org/10.1177/2156587217717416

Rafieian-kopaei M. Shakiba A. Sedighi M. Bahmani M 2017b. The Analgesic and AntiInflammatory Activity of Linum usitatissimum in Balb/c Mice. Journal of Evidence-Based Complementary and Alternative Medicine, 22(4), 892-896. https://doi.org/10.1177/2156587217717416

Sasseville D 2008. Occupational contact dermatitis. Allergy, Asthma and Clinical Immunology. 
https://doi.org/10.2310/7480.2008.00010

Sewell RDE. Spencer PSJ 1976. Antinociceptive activity of narcotic agonist and partial agonist analgesics and other agents in the tail-immersion test in mice and rats. Neuropharmacology. https://doi.org/10.1016/0028-3908(76)90037-X

Singh S. Nair V. Gupta YK 2012. Linseed Oil: An investigation of its antiarthritic activity in experimental models. Phytotherapy Research, 26(2), 246-252. https://doi.org/10.1002/ptr.3535

Soušek J. Guédon D Adam, T. Bochořáková H. Táborská E. Válka I. Šimánek V 1999. Alkaloids and organic acids content of eight Fumaria species. Phytochemical Analysis. https://doi.org/10.1002/(SICI)1099-1565(199901/02)10:1<6::AID-PCA431>3.0.CO;2-0

Statile L. Puig MM. Warner W. Bansinath M. Lovitz M. Turndorf H 1988. Droperidol enhances fentanyl and sufentanil, but not morphine, analgesia. General Pharmacology, 19(3), 451-454. https://doi.org/10.1016/0306-3623(88)90046-8

Sugimoto MA. Sousa LP. Pinho V. Perretti M. Teixeira MM 2016. Resolution of Inflammation: What Controls Its Onset? Frontiers in Immunology, 7, 160. https://doi.org/10.3389/fimmu.2016.00160

Tjølsen A. Berge OG. Hunskaar S. Rosland JH. Hole K 1992. The formalin test: an evaluation of the method. In Pain. https://doi.org/10.1016/0304-3959(92)90003-T

Vergnolle N 2003. The Inflammatory Response. Drug Development Research, 381, 375-381. https://doi.org/10.1002/ddr.10306

Ward PA. Lentsch AB 1999. The acute inflammatory response and its regulation. Archives of surgery (Chicago, Ill. : 1960), 134(6), 666-669. https://doi.org/10.1001/archsurg.134.6.666. 